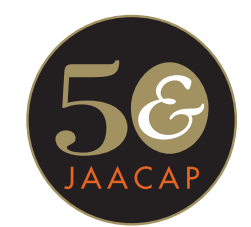

\title{
Standardized Interviews for Diagnostic Assessments of Children and Adolescents in Psychiatric Research
}

\author{
Myrna M. Weissman, Ph.D.
}

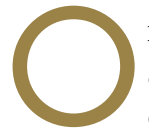

ne article alone rarely changes a field and usually reflects the point prevalence of accumulated research. Moreover, any method-no matter how innovative at the timeevolves because cumulative scientific discoveries challenge existing paradigms. Nonetheless, two articles published in the Journal of the American Academy of Child and Adolescent Psychiatry on standardized diagnostic interviews stand out as research landmarks in the psychiatric assessment of children and adolescents: one by Orvaschel et al. in $1982^{1}$ and another by Kaufman et al. in $1997 .^{2}$

I will present a historical context. The introduction of DSM-III, which included specific diagnostic criteria, improved reliability and interview tools for collecting the information to make diagnostic criteria and facilitated the modern age of psychiatric epidemiology. Beginning in the early 1980s, the first survey, the Epidemiologic Catchment Area Study, collected data on psychiatric disorders in the community and used these methods. The resulting finding on rates, risks, age of onset, and comorbidity, derived from 18,000 adults in five U.S. communities, were incorporated into research studies and clinical descriptions of psychiatric disorders. ${ }^{3}$ The Epidemiologic Catchment Area Study was followed by new and improved surveys in each subsequent decade. ${ }^{4,5}$ The major finding, consistent throughout the decades and shown clearly in the Epidemiologic Catchment Area Study, was that most psychiatric disorders usually had their first onset in childhood and adolescence. This finding accelerated the importance of psychiatric research in children. However, the direct assessment of children and adolescents lagged way behind the methods used in community studies of adults. Even today, there are few community surveys of children and adolescents in the United States. ${ }^{6}$
Knowing that psychiatric disorders first begin in childhood led naturally to questions about early signs and symptoms of disorders, especially in children at high risk. The family/genetic studies of adults with major depressive disorder (MDD), bipolar disorder, and schizophrenia that began in the 1980s were fueled by the availability of reliable diagnostic assessments and the nascent promise of genetics. Family studies of depression showed that early onset major depressive disorder (MDD) in childhood or adolescence was the most familial, suggesting that it might be the most genetic. ${ }^{7}$ However, children were excluded from these studies. Reports of age of onset of psychiatric disorders were retrospective ageof-onset reports of and by adults. These age-ofonset findings on rates and familial risk made more direct study of young people even more important. A series of studies of children at high risk for major psychiatric disorders began in the mid-1980s. High-risk studies are a variant of family studies, with the focus usually on the biological offspring of the ill or the control biological parents (top-down studies). They can also begin with the ill child and proceed to the study of the parents (bottom-up). If the offspring are studied longitudinally, early signs of illness and their developmental unfolding can be determined. Moreover, risk factors that are premorbid rather than concomitant with, or manifestations of, the disorder may be detected. ${ }^{8-10}$ Identifying vulnerable individuals or periods have implications for prevention and future intervention. These study designs have recently proved to be potentially useful in searching for endophenotypes as modern methods of imaging and electroencephalography have been incorporated. ${ }^{11}$

A major obstacle in the conduct of the studies was the availability of systematic interviews for the direct diagnostic assessment of children and adolescents. The late Joaquim Puig-Antich, who had an 
untimely death in 1989, was a maverick in child psychiatry. Working with Robert Spitzer at Columbia in the 1970s, Puig-Antich modified the Schedule for Affective Disorders and Schizophrenia (SADS) so that it was appropriate for children and adolescents. He called it the Kiddie-SADS or K-SADS. The K-SADS was a standardized interview for collecting signs and symptoms that could be used to make DSM-III diagnoses. At a time when there was a question about whether childhood depression existed, he began a series of studies in depression in children using the K-SADS. Likely due to disinterest in the field, the K-SADS remained unpublished until the 1982 publication in the Journal by Orvashel et al. ${ }^{1}$ Their article presented data on the accuracy of retrospective diagnosis in a small sample. It was the first publication of the K-SADS. The K-SADS became increasingly used in high-risk and other studies of children 6 to 17 years of age. Several subsequent homegrown versions of the K-SADS to fit different studies and tastes appeared over the years. In 1997, Kaufman et al. presented an updated version of the K-SADS with improved probes, anchor points, specific impairment criteria, and an ability to generate DSM-III-R and DSM-IV criteria. $^{2}$ The Kaufman version superseded the many other revisions and its pivotal first report was published in the Journal.

However, an editorial for a 50th anniversary of a journal publishing innovative research must not only look back in time. The methods developed by Orvaschel, Puig-Antich, Kaufman, and others in the 1980s and 1990s will be updated as the DSM- $V$ appears. Their methods have been and will continue to be an important part of targeted clinical studies where precise phenotypes are needed. However, for epidemiologic studies, they were too lengthy and required clinically trained interviewers. They have been since been revised, shortened, and simplified for large-scale epidemiologic studies.

Newer ways of considering diagnosis called the National Institute of Mental Health Research Domain Criteria Project are being developed. ${ }^{12,13}$ They will not replace DSM but will complement and cut across disorders as investigators attempt to get closer to the mechanism underlying the biology of diagnosis. The project is designed to classify mental disorders based on dimensions of

\section{REFERENCES}

1. Orvaschel H, Puig-Antich J, Chambers W, Tabrizi MA, Johnson R. Retrospective assessments of prepubertal major depression with Kiddie-SADS-E. J Am Acad Child Adolesc Psychiatry. 1982;21: 392-397. observable behavior and neurobiological measurements. Whether this new approach will bring us closer to understanding the pathway toward psychiatric illness, will be linked to pathophysiology, will identify biomarkers, and will lead to personalized treatment is still unclear, but certainly worth the effort. The Research Domain Criteria Project criteria are still in draft form. The final revision will need to have systematic assessments and procedures for obtaining the clinical information. The work of Orvaschel, Puig-Antich, and Kaufman provide an important historical context and a standard for this process. $\varepsilon$

Accepted August 5, 2010

In celebration of its 50 th anniversary, the Journal presents a year-long series of editorials that discuss and reflect upon pivotal research published in these pages over the past five decades. The editorials show how the foundations of the science in child and adolescent psychiatry have been laid, describe how they influence us today, and suggest how they will continue to guide us over the next fifty years and on.

Dr. Weissman is a Professor of Epidemiology in Psychiatry, College of Physicians and Surgeons and the Mailman School of Public Health at Columbia University and Chief of the Division of Epidemiology at New York State Psychiatric Institute. She is a member of the Institute of Medicine, National Academy of Science. Until 1987, she was a Professor of Psychiatry and Epidemiology at Yale University School of Medicine. She received a Ph.D. in epidemiology from the Yale University School of Medicine in 1974. Her current research is on understanding the rates and risks of mood and anxiety disorders using methods of epidemiology, genetics, and neuroimaging and the application of these findings to develop and test empirically based treatments and prevention intervention. She has been the recipient of numerous grants from the National Institute of Mental Health (NIMH) and private foundations and numerous awards for her research. In April 2009, she was selected by the American College of Epidemiology as 1 of 10 epidemiologists in the United States who has had a major impact on public policy and health. The summary of her work on depression appeared in a special issue, Triumphs in Epidemiology, of the Annals of Epidemiology.

This work was supported in part by NIMH/RO1 MH36197, Children at High and Low Risk for Depression.

Disclosure: Dr. Weissman has received funding from the NIMH, the National Institute on Drug Abuse, the National Alliance for Research on Schizophrenia and Depression, the Sackler Foundation, the Templeton Foundation, and the Interstitial Cystitis Association. She receives royalties from Oxford University Press, Perseus Press, the American Psychiatric Association Press, and MultiHealth Systems.

Correspondence to Myrna M. Weissman, Ph.D., Professor of Epidemiology in Psychiatry, Department of Psychiatry, College of Physicians and Surgeons, Columbia University, Chief, Division of Epidemiology, New York State Psychiatric Institute, 1051

Riverside Drive, Unit 24, New York, NY 10032; e-mail: mmw3@ columbia.edu

0890-8567/\$36.00/@2011 American Academy of Child and Adolescent Psychiatry

DOI: 10.1016/i.jaac.2010.07.015

2. Kaufman J, Birmaher B, Brent D et al. The Schedule for Affective Disorders and Schizophrenia for School Aged Children: Present and Lifetime Version (KSADS-PL): initial reliability and validity data. J Am Acad Child Adolesc Psychiatry. 1997;36:980-988. 
3. Robins LN, Regier DA, eds. Psychiatric Disorders in America: The Epidemiologic Catchment Area Study. New York: Free Press; 1991.

4. Kessler RC, McGonagle KA, Zhao S et al. Lifetime and 12-month prevalence of DSM-III-R psychiatric disorders in the United States. Results from the National Comorbidity Survey. Arch Gen Psychiatry. 1994;51:8-19.

5. Grant BF, Stinson FS, Dawson DA et al. Prevalence and cooccurrence of substance use disorders and independent mood and anxiety disorders: results from the National Epidemiologic Survey on Alcohol and Related Conditions. Arch Gen Psychiatry. 2004;61:807-816.

6. Szatmari P. More than counting: milestones in child and adolescent psychiatric epidemiology. J Am Acad Child Adolesc Psychiatry. 2009;48:353-355.

7. Weissman MM, Wickramaratne P, Merikangas KR et al. Onset of major depression in early adulthood: increased familial loading and specificity. Arch Gen Psychiatry. 1984;41:1136-1143.
8. Hammen C, Burge D, Burney E, Adrian C. Longitudinal study of diagnoses in children of women with unipolar and bipolar affective disorder. Arch Gen Psychiatry. 1990;47:112-117.

9. Lieb R, Isensee B, Hofler M, Pfister H, Wittchen H-U. Parental major depression and the risk of depression and other mental disorders in offspring. Arch Gen Psychiatry. 2002;59: 365-374.

10. Weissman MM, Wickramartne P, Nomura Y, Warner V, Pilowsky D, Verdeli H. Offspring of depressed parents: 20 years later. Am J Psychiatry. 2006;163:1001-1008.

11. Peterson BS, Warner V, Bansal $\mathrm{R}$ et al. Cortical Thinning in Persons At Increased Familial Risk For Major Depression. Proc Natl Acad Sci U S A. 2009;106:6273-6278.

12. Insel $\mathrm{T}$, Cuthbert $\mathrm{B}$, Garvey $\mathrm{M}$ et al. Research Domain Criteria (RDoC): toward a new classification framework for research on mental disorders. Am J Psychiatry. 2010;167:748-751.

13. Miller G. Psychiatry. Beyond DSM: seeking a brain-based classification of mental illness. Science. 2010;327(5972):1437. 